\title{
Penanaman Budaya 5S (Senyum, Sapa, Salam, Sopan, Santun) pada Siswa Sekolah Dasar
}

\author{
Nurul Auliani Husna1, Santoso ${ }^{2}$, Erik Aditia Ismaya ${ }^{3}$ \\ 1,2,3Pendidikan Guru Sekolah Dasar, Fakultas Keguruan dan Ilmu Pendidikan, \\ Universitas Muria Kudus, Indonesia \\ E-mail: nurulauliani76@gmail.com,santoso.pgsd@umk.ac.id,erik.aditia@umk.ac.id
}

\begin{abstract}
Article Info
Article History

Received: 2021-12-27

Revised: 2022-01-22

Published: 2022-02-04

Abstract

This research is a classroom action research with the application of the Low-Skill Friends method that aims to increase student learning activities and outcomes. The sample used in this study was 35 high school students of Manggelewa class X IPA 1, amounting to 35 people. The results of data analysis obtained the percentage of student learning activities in the learning process without applying the Low-Skill

Keywords:

Low-Skill Friends; Activities; Friends method, cycle I and cycle II respectively $52.78 \%, 70.83 \%$ and $90.28 \%$. From

Learning outcomes. these results obtained a very significant recall of student learning activities that is equal to $37.50 \%$. While the results of analysis on student learning outcomes obtained in the learning process without applying the Low-Skill Friends method, cycle I and Cycle II respectively $48.57 \%, 74.29 \%$ and $94.29 \%$. From these results also obtained a very significant recall of student learning activities that is equal to $45.72 \%$. The increase in learning activities and outcomes is due to the habits of students who have below average ability to participate in the problem solving process. This habit arises spontaneously from students as a result of feeling there are students who have low abilities just like him.
\end{abstract}

\begin{tabular}{l}
\hline Artikel Info \\
\hline Sejarah Artikel \\
Diterima: $2021-12-27$ \\
Direvisi: $2022-01-22$ \\
Dipublikasi: $2022-02-04$
\end{tabular}

Kata kunci:

Budaya 5S;

Penanaman Budaya;

Pendidikan Karakter.

\begin{abstract}
Abstrak
Penelitian ini bertujuan untuk menanamkan budaya 5S (Senyum, Sapa, Salam, Sopan, Santun) pada siswa Sekolah Dasar di Desa Margorejo, Kecamatan Dawe, Kabupaten Kudus, dengan rumusan masalah mendeskripsikan penanaman budaya 5S (Senyum, Sapa, Salam, Sopan, Santun) pada siswa Sekolah Dasar dan menganalisis faktor pendukung dan penghambat dalam penanaman budaya 5S pada siswa Sekolah Dasar. metode deskriptif kualitatif sebagai tahapan melaksanakan penelitian. Penelitian ini dilakukan di Desa Margorejo Kecamatan Dawe Kabupaten Kudus dengan subyek penelitian Orangtua Siswa dan siswa sekolah dasar, sebagai subjektif. Penelitian ini menggunakan teknik pengumpulan data meliputi tahap observasi, wawancara, dan dokumentasi. Analisis data yang digunakan merupakan analisis data deskriptif kualitatif. Hasil penelitian ini menunjukkan bahwa dari keenam siswa SD di desa Margorejo yang dijadikan subjek penelitian memiliki sikap yang kurang peduli terhadap sekitar dan kurangnya sikap sopan santun siswa. Selain itu, sikap siswa yang cenderung berubah-ubah sesuai dengan kondisi yang dialami siswa saat itu. Kesimpulan penelitian ini menunjukkan bahwa siswa memerlukan dukungan dari orangtua untuk menanamkan dan membiasakan 5S dengan cara memberikan contoh baik agar anak dapat mencontohnya.
\end{abstract}

\section{PENDAHULUAN}

Perkembangan zaman yang semakin maju sangatlah mempengaruhi pendidikan sosial dan budaya pada anak usia sekolah dasar, pendidikan adalah suatu usaha yang digunakan untuk membimbing dan menuntun peserta didik menjadi lebih berguna bagi bangsa Indonesia. Karena pada dasarya pendidikan bukan hanya untuk memberikan ilmu kepada peserta didik ketika di sekolah maupun diluar sekolah akan tetapi dapat mendidik peserta didik untuk bisa menjadi generasi bangsa yang mempunyai jati diri yang berkualitas untuk negara. Suatu kegiatan mendidik tidak hanya kita lakukan disuatu lembaga pendidikan saja akan tetapi kegiatan mendidik dilakukan dimana saja baik di lingkungan sekolah, masyarakat, dan keluarga. Sudrajat (2011: 47) pendidikan merupakan suatu yang dilakukan seseorang dalam sepanjang hidupnya sebagai sarana dalam mendidik dan mengajarkan peserta didik dalam melakukan suatu proses pembelajaran baik berupa nilai maupun ilmu pengetahuan. Seiring perkembangan ilmu pengetahuan yangberkembang secara tidak langsung juga mempengaruhi perilaku peserta didik, saat ini banyak dilihat di tengahtengah lingkungan sekolah banyak para guru dan generasi muda yang tak terkecuali anak sekolah 
dasar yang jarang menerapkan budaya 5S (Senyum, Sapa, Salam, Sopan, Santun), budaya 5S menjadi luntur disebakan oleh salah satu faktor yaitu meniru kehidupan kebarat-baratan, karena saat ini sangat mudah untuk mengakses perilaku kehidupan Negara lain yang cenderung egois dan hedonis.

Pada kondisi sekarang ada faktor eksternal yang terealisasikan secara realita kebudayaan yang terus berubah-ubah karena banyaknya budaya barat yang masuk yang akan mempersulit untuk mempertahankan sopan santun dimanapun dan kapanpun, selain tidak sopan terhadap orangtuanya sendiri, bahwa anak jaman sekarang juga ada yang tidak sopan dengan orang sekitar yang lebih tua darinya dengan cara ketika memanggil menyebut nama orang langsung, ada lagi cara berpakaian anak-anak muda jaman sekarang yang kebarat-baratan dengan meniru budaya barat yang memang kurang cocok untuk Indonesia yang lebih condong ke budaya timur (Gufron, 2010:13), adapun faktor internal yang mempengaruhi hilangnya sopan santun siswa Indonesia itu pada diri siswa itu sendiri, keluarga, lingkungan, tempat nongkrong, lingkungan sekolah, ataupun media masa. Suryani (2017:113) menyatakan bahwa penyebab perilaku kurang sopan diduga dipengaruhi oleh pergaulan siswa yang kurang terkontrol oleh orangtua, kurangnya bimbingan dari guru serta perilaku coba-coba dari siswa, perilaku siswa perlu dibentuk mulai dari pendidikan usia dini, karena hal tersebut dapat mempengaruhi perkembangan pendidikan selanjutnya. Pada penelitian penanaman budaya 5S (Senyum, Sapa, Salam, Sopan, Santun) pada siswa sekolah dasar yang dilaksanakan di desa Margorejo Kecamatan Dawe Kabupaten Kudus akan terfokuskan pada 6 siswa dan 6 orangtua siswa, karena akhir-akhir ini sudah mulai terkikisnya nilai moral atau akhlak pada siswa di lingkungan masyarakat dan juga di lingkungan sekolah disebabkan oleh pengaruh lingkungan sekitar dan juga kurangnya orangtua dalam membiasakan 5S pada anaknya. Norbayah ( 2017 :9) menyatakan bahwa memang tidak mudah dalam menanamkan budaya $5 \mathrm{~S}$ di kalangan siswa Sekolah Dasar, sebab banyak diantara mereka yang kurang terbiasa, hal ini diduga disebabkan hal yang sama yaitu kurang dibiasakan dalam lingkungan keluarga.

Sebelunya telah banyak riset yang dilakukan, antara lain oleh Maulidah (2019). Hasil penelitian ini menunjukkan bahwa manajemen program tersebut sudah baik. manajemen tersebut meliputi perencanaan, pelaksanaan, dan evaluasi. Proses perencanaan program tersebut sudah masuk dalam kurikulum sekolah, namun tidak memiliki jam pelajaran khusus melainkan aktivitas budaya warga sekolah, budaya ini melalui pembiasaan Budaya 5S di lingkungan sekolah, tugas guru, staff dan karyawan sebagai pelaksana, sedangkan siswa sebagai objeknya. Berdasarkan latar belakang tersebut dapat diketahui bahwa menanamkan budaya 5S (Senyum, Sapa, Salam, Sopan, Santun) pada siswa sekolah dasar sangatlah penting untuk membentuk karakter siswa sekolah dasar menjadi lebih baik, maka peneliti tertarik untuk melakukan penelitian dengan judul "Penanaman Budaya 5S (Senyum, Sapa, Salam, Sopan, Santun) Pada Siswa Sekolah Dasar".

\section{METODE PENELITIAN}

Penelitian ini dilakukan dengan menggunakan penelitian kualitatif dan analisis data secara deskriptif, Sugiyono (2015:15) menyatakan bahwa metode penelitian kualitatif adalah metode penelitian yang berlandaskan pada fislafat postpositivisme yang digunakan untuk meneliti kondisi obyek yang alamiah, dimana peneliti sebagai instrument kunci dan hasilnya lebih menekankan makna dari pada generalisasi, penelitian kualitatif ini dilakukan dengan mengutamakan kedalaman penghayatan konsep yang dikaji secara empiris dan teknik pengumpulan data dilakukan menggunakan teknik pengumpulan data melalui wawancara, observasi, dan dokumentasi. Sumber data pada penelitian ini bersumber dari data primer dan data sekunder. Data primer menurut Sugiyono (2015) adalah sumber data yang langsung memberikan data kepada pengumpul data. Informan terpilih yaitu orang tua Siswa SD di Desa Margorejo dan siswa Sekolah Dasar tepatnya di Desa Margorejo Kecamatan Dawe Kabupaten Kudus. Sedangkan data sekunder menurut Sugiyono (2015) adalah sumber data yang tidak langsung memberikan data kepada pengumpul data, misalnya lewat orang lain atau lewat dokumen. Sumber data sekunder berasar dari dokumentasi penelitian, catatan hasil wawancara, foto-foto serta data pendukung lainnya.

Analisis data yang digunakan yaitu model Milles Huberman yang disajikan secara interaktif. Aktivitas dalam analisis data, yaitu, data reduction, data display dan conclusion drowing/ verification (Sugiyono, 2015). Reduksi data berarti merangkum, memilih hal-hal yang pokok, memfokuskan pada hal-hal yang penting, berkaitan dengan penanaman budaya 5S (Senyum, 
sapa, salam, Sopan dan santun) pada siswa Sekolah dasar. Selanjutnya penyajian data berupa tindakan yang dilakukan untuk menanamkan budaya 5S (Senyum, sapa, salam, Sopan dan santun) pada siswa Sekolah dasar serta faktor yang mendukung dan menhambat dalam penanaman budaya 5S (Senyum, sapa, salam, Sopan dan santun) pada siswa Sekolah dasar berupa uraian kata-kata dan deskripsi kata. Kemudian, peneliti mengambil kesimpulan atas permasalahan penelitian yaitu tentang penanaman budaya 5S (Senyum, sapa, salam, Sopan dan santun) pada siswa Sekolah dasar di Desa Margorejo Kecamatan Dawe Kabupaten Kudus.

\section{HASIL DAN PEMBAHASAN}

Berikut deskripsi dan pembahasan hasil analisis data yang sudah di peroleh dari hasil penelitian yaitu:

1. Penanaman budaya 5S pada siswa Sekolah Dasar yang ada di Desa Margorejo Kecamatan Dawe Kabupaten Kudus dapat tertanam dengan adanya pembiasaan-pembiasaan baik yang diterapkan di lingkungan desa. Budaya 5S yaitu Senyum, Sapa, Salam, Sopan, dan Santun. Siswa Sekolah Dasar yang ada di Desa Margorejo Kecamatan Dawe Kabupaten Kudus diharapkan untuk memiliki sikap ramah seperti berbicara dengan sopan dan bertegur sapa apabila bertemu dengan seseorang, memiliki etika seperti terbiasanya siswa mengatakan kata maaf dan terimakasih, memiliki sikap ramah seperti terbiasanya siswa untuk memberikan senyuman, sapaan, dan salam kepada seseorang, peduli sesama seperti terbiasanya siswa untuk saling berbagi kepada orang yang membutuhkan, dan diharapkan siswa selalu menjunjung tinggi etika budaya seperti terbiasanya siswa untuk bertutur kata jujur dalam kehidupan seharihari. Peran orangtua dalam menanamkan budaya 5S (Senyum, Sapa, Salam, Sopan, Santun) sangatlah penting dalam pembentukan karakter anak serta membiasakan pengaruh besar dalam keberhasilan penanaman budaya 5S pada siswa Sekolah Dasar, dalam upaya pembentukan generasi penerus yang baik secara iman, taqwa dan akhlak yang terpuji perlu ditanamkan dan dibiasakan melakukan 5S pada semua orang sedini mungkin. Ginanjar (2013:234) menyatakan bahwa seorang anak adalah generasi yang datang. Hitam dan putihnya generasi yang akan datang sangat ditentukan oleh kegigihan para orangtua dalam menanamkan karakter serta nilai-nilai atau ajaran agama yang benar. Orangtua merupakan pendidik utama dan pertama bagi anak-anak mereka, karena dari merekalah anak mula-mula menerima pendidikan dengan demikian bentuk dari pertama pendidikan dalam kehidupan keluarga, orangtua (ayah dan ibu) memegang peranan penting dan amat berpengaruh atas pendidikan anak-anaknya, sejak seorang anak lahir, ibulah yang selalu ada disampingnya (Nur Afni, 2020: 132).

Sebagaimana dengan informasi yang diperoleh dari hasil proses wawancara dengan subjek siswa Sekolah Dasar terkait sikap ramah, perilaku, etika, sikap hormat dan peduli sesama dalam penanaman budaya $5 \mathrm{~S}$ (Senyum, Sapa, Salam, Sopan, Santun. Narasumber yang pertama yakni CD, dalam proses wawancara ia mengatakan:

"Orangtuaku membiasakan saya sebelum berangkat sekolah bersalaman dan berpamitan kepada orangtua terlebih dahulu, kalau dirumah juga saya jarang membantah orangtua, tapi saya sering membantu orangtua saya membersihkan rumah. Kalau dengan temantemanku saya akrab, kalau ada teman yang meminta tolong atau membutuhkan bantuan saya bantu, saya dengan tetangga kurang kenal tapi kalau saya melewati mereka saya mbungkuk."(Wawancara tanggal 15 November 2021).

Selain mewawancarai CD peneliti pun melakukan wawancara dengan siswa Sekolah Dasar lainnya di Desa Margorejo. Saat wawancara DPS mengatakan:

"Kebiasaan saya setiap harinya membantu ibu, terkadang saya membantu menyapu, membantu membereskan kamarku, dan terkadang membantu memasak, di sekolah saya punya banyak teman, dirumah juga saya punya banyak teman, kalau disekolah saya biasa meminjami alat tulis kepada teman saya, kalau dirumah saya berbagi mainan dengan temanku, saya berteman dengan semuanya, saya tidak memilih-milih teman" (Wawancara tanggal 18 November 2021).

Untuk memperkuat pernyataan tersebut, peneliti mewancarai siswa sekolah dasar lainnya terkait penanaman budaya 5S, SW mengatakan:

"Setiap hari saya membantu ibu saya menyapu rumah dan halaman terkadang saya juga membantu ibu cuci baju kalau saya pulang sekolah dan ibuku lagi kerja saya menemani adiku bermain dirumah, saya sering bermain 
dengan teman-temanku didesa, kalau saya beli jajan saya begi ke mereka, saya kalau lewat rumah orang yang tidak saya kenali, kalau orangnya didepan rumah saya tidak menyapanya tapi hanya menundukkan kepala" (Wawancara tanggal 15 November 2021).

Berdasarkan hasil wawancara yang dilakukan kepada siswa sekolah dasar maka dapat disimpulkan penanaman budaya $5 \mathrm{~S}$ (Senyum, Sapa, Salam, Sopan, Santun) pada siswa dasar Desa Margorejo dilakukan dengan cara berupa membantu membersihkan rumah, bersalaman dengan orang tua sebelum berangkat ke sekolah ataupun pergi bermain, saling membantu kepada sesama temannya, saling membantu dilingkungan masyarakat, mematuhi orang tua, meminjami peralatan sekolah kepada teman, berkata jujur dan menjaga kebersihan dengan cara membuang sampah pada tempatnya. Sikap yang dimiliki para siswa tak luput dari peran orang tua yang memberikan penanaman budaya 5S (Senyum, Sapa, Salam, Sopan, Santun), selain melakukan wawancara dengan subjek siswa Sekolah Dasar, peneliti pun melakukan wawancara dengan orang tua siswa untuk mengkonfirmasi penanaman budaya 5S (Senyum, Sapa, Salam, Sopan, Santun) yang diberikan, narasumber yang pertama yakni Ibu HK, saat proses wawancara beliau mengatakan:

"Saya sebagai orang tua selalu membiasakan anak dirumah untuk disiplin dan bertanggung jawab, kemudian menasehati anak agar hormat dengan orang tua, maupun orang lain, menjaga sopan santun, mencotohkan anak untuk salin tolong menolong, saya orangnya tegas juga, kalau anak tidak bisa di bilangin saya marahin tetapi dengan kata-kata yang baik tentunya" (Wawancara tanggal 15 November 2021).

Sejalan dengan pernyataan oleh Ibu HK, peneliti juga melakukan wawancara dengan Ibu SH terkain penanaman budaya 5S, saat proses wawancara beliau mengatakan:

"Saya selalu membiasakan anak agar tidak malu jika bertemu orang lain, disapa kalau bertemu orang lain kalau tidak ya membungkukkan badan. Kemudian, dirumah saya sering mengajak anak saya berkejasa sama tolong menolong membersihkan rumah, saya selalu menjaga komunikasi dengan anak saya, saya selalu berpesan meskipun salah harus berkata jujur, karna jujur itu kunci dari semua masalah, saya tidak pernah memarahi anak saya, bukan berarti saya memanjakanya, tapi lebih memberikan pengertian dan batasanbatasan mana saja yang harus anak lakukan".

(Wawancara tanggal 18 November 2021)

Hal sama juga dituturkan oleh Ibu SP dalam memberikan penanaman budaya $5 \mathrm{~S}$ (Senyum, Sapa, Salam, Sopan, Santun) terhadap anak. Saat prose wawancara beliau mengatakan:

"Saya memberikan pembiasaan-pembiasaan ke anak jika dirumah, seperti harus meminta izin terlebih dahulu jika pergi, terus kalau bertemu orang harus menyapa, menjaga sopan santun. Kadang saya juga berpesan ke anak, kalau bermain ya yang baik, saling menghargai, jangan membeda-bedakan teman, dan tolong menolong antar sesama" (Wawancara tanggal 19 November 2021).

Berdasarkan hasil wawancara dapat disimpulkan bahwa orang tua memberikan peran penting dalam penanaman buadaya $5 \mathrm{~S}$ (Senyum, Sapa, Salam, Sopan, Santun) di lingkungan desa Margorejo, hal ini ditujukan memberi contoh sikap, perilaku dan tindakan kepada anak ataupun siswa Sekolah Dasar yang ada di Desa Margorejo Kecamatan Dawe Kabupaten Kudus, penanaman budaya 5S pada siswa SD yang ada di Desa Margorejo Kecamatan Dawe Kabupaten Kudus dengan pembiasaan-pembiasaan baik yang dilakukan sedini mungkin, dimulai dengan melatih anakanak untuk bersikap baik dan sopan ketika bertemu dengan orangtua yang ada dilingkungan desa, dari temuan-temuan yang peneliti temukan berdasarkan proses wawancara dan observasi, peneliti akan menyajikannya dalam table sebagai berikut:

Tabel 1. Penanaman Budaya 5S

\begin{tabular}{|c|c|c|}
\hline $\begin{array}{c}\text { Penanaman Budaya 5S oleh } \\
\text { Orang Tua }\end{array}$ & & $\begin{array}{c}\text { Realisasi Budaya 5S } \\
\text { oleh Siswa }\end{array}$ \\
\hline $\begin{array}{l}\text { 1. Pembiasaan berbicara yang } \\
\text { sopan terhadap orang tua } \\
\text { 2. Pembiasaan berbicara jujur } \\
\text { terhadap siapa saja } \\
\text { 3. Pembiasaan bersikap baik } \\
\text { terhadap orang lain } \\
\text { 4. Pembiasaan untuk me- } \\
\text { nghormati dan meng-hargai } \\
\text { orang lain } \\
\text { 5. Peneladanan sikap sa-ling } \\
\text { membantu } \\
\text { 6. Peneladanan sikap sal-ing } \\
\text { tegur sapa }\end{array}$ & 4. & $\begin{array}{l}\text { Meminta izin apa-bila } \\
\text { pergi keluar rumah/ } \\
\text { sekolah } \\
\text { Berpamitan apabila } \\
\text { pergi keluar rum-ah/ } \\
\text { sekolah } \\
\text { Membantu orang tua } \\
\text { mengerjakan } \\
\text { pekerjaan rumah } \\
\text { Mematuhi perintah } \\
\text { orang tua } \\
\text { Berbicara sopan } \\
\text { dengan orang yang } \\
\text { lebih tua } \\
\text { Menjaga sikap so-pan } \\
\text { dan santun terhadap } \\
\text { orang lain } \\
\text { Memberikan salam }\end{array}$ \\
\hline
\end{tabular}




\begin{tabular}{|c|c|}
\hline $\begin{array}{c}\text { Penanaman Budaya } 5 S \text { oleh } \\
\text { Orang Tua }\end{array}$ & $\begin{array}{c}\text { Realisasi Budaya 5S } \\
\text { oleh Siswa }\end{array}$ \\
\hline & $\begin{array}{l}\text { jika bertemu orang } \\
\text { lain } \\
\text { 8. } \begin{array}{l}\text { Bertegur sapa de- } \\
\text { ngan teman }\end{array} \\
\text { 9. Saling membantu } \\
\text { antar teman } \\
\text { 10. } \begin{array}{l}\text { Tidak membeda- } \\
\text { bedakan teman }\end{array} \\
\text { 11. } \begin{array}{l}\text { Berkata jujur ter- } \\
\text { hadap teman }\end{array} \\
\text { 12. } \begin{array}{l}\text { Saling memberi } \\
\text { dengan teman }\end{array} \\
\text { 13. } \begin{array}{l}\text { Saling memaafkan } \\
\text { dengan teman }\end{array}\end{array}$ \\
\hline
\end{tabular}

Berdasarkan tabel diatas dapat kita lihat bahwa penanaman budaya $5 \mathrm{~S}$ pada siswa Sekolah Dasar yang ada di Desa Margorejo, Kecamatan Dawe, Kabupaten Kudus dapat tertanam dengan adanya pembiasaan-pembiasaan baik yang diterapkan dilingkungan rumah, budaya 5S yaitu Senyum, Sapa, Salam, Sopan dan Santun. Siswa Sekolah Dasar yang ada di Desa Margorejo Kecamatan Dawe Kabupaten Kudus memiliki sikap ramah seperti berbicara dengan sopan dan bertegur sapa apabila bertemu dengan seseorang, memiliki etika seperti terbiasanya siswa mengatakan kata maaf dan terimakasih, memiliki sikap ramah seperti terbiasanya siswa untuk memberikan senyuman, sapaan, dan salam kepada seseorang, peduli sesama seperti terbiasanya siswa untuk saling berbagi kepada orang yang membutuhkan, dan diharapkan siswa selalu menjunjung tinggi etika budaya seperti terbiasanya siswa untuk bertutur kata jujur dalam kehidupan seharihari.

2. Faktor pendukung dan penghambat dalam penanaman budaya 5S (Senyum, Sapa, Salam, Sopan, Santun) pada siswa Sekolah Dasar

Penanaman budaya 5S (Senyum, sapa, salam, sopan dan santun) pada siswa Sekolah dasar tidak serta merta berjalan dengan baik, hal ini dapat dipengaruhi oleh beberapa faktor dalam menanamkan budaya $5 \mathrm{~S}$ kepada siswa, faktor-faktor yang mempengaruhi pembiasaan budaya 5S (Senyum, Sapa, Salam, Sopan, Santun) di lingkungan sekolah terhadap siswa adalah adanya hubungan baik antar warga sekolah, keluarga, dan masyarakat, adapun faktor-faktor yang mempengaruhi budaya 5S (Senyum, Sapa, Salam, Sopan, Santun) menurut (Putri, 2020: 40-42) diantaranya kurikulum, lingkungan Sekolah, lingkungan Keluarga dan lingkungan masyarakat. Sedang- kan faktor penghambat yaitu Lingkungan Keluarga, orangtua tidak begitu paham apa sebenarnya tujuan dari sekolah itu sendiri, bagi mereka yang penting menyekolahkan anaknya, hal ini biasa terjadi pada orangtua yang terlalu sibuk dengan urusannya sehingga waktu untuk anaknya terbatas dan akhirnya anak kurang diperhatikan oleh orangtuanya, terutama sikap dan perilaku yang lepas dari pengawasan dalam menanamkan karakter sopan santun, karena partisipasinya dan dukungan dari orangtuanya kurang, kemudian Lingkungan Masyarakat, anak-anak bergaul dengan orang yang lebih dewasa dan orang tersebut membawa dampak buruk bagi anak, anak bukannya diajarkan hal-hal positif melainkan hal negatif.

\section{SIMPULAN DAN SARAN}

\section{A. Simpulan}

Berdasarkan hasil temuan data dan pembahasan, peneliti menyimpulkan bahwa Penanaman budaya 5S (Senyum, Sapa, Salam, Sopan, Santun) melalui memberi contoh sikap, perilaku dan tindakan serta pembiasaanpembiasaan baik yang dilakukan sedini mungkin oleh orang tua terhadap anak-anak sekolah dasar di Desa Margorejo, bentuk dari penanaman budaya $5 \mathrm{~S}$ tersebut berupa anak yang sudah mampu menyapa seorang yang ditemuinya, bersalaman dengan orang tua, saling membantu sesama, saling toleransi, mematuhi orang tua, bertutur kata dengan sopan, berkata jujur dan menjaga kebersihan dengan cara membuang sampah pada tempatnya. Selain itu terdapat faktor pendukung dalam penanaman budaya $5 \mathrm{~S}$ yaitu terdapat lingkungan sekitar khususnya keluarga orang tua yang memberikan contoh dengan baik agar anaknya menirukan tidakan dan sikap tersebut serta terdapat orang tua yang memberikan efek jera kepada anak. Sedangkan faktor penghambat dalam penanaman budaya $5 \mathrm{~S}$ pada siswa sekolah dasar yaitu orang tua tidak memperhatikan keberadaan sosialisasi di lingkungan sekitar dan memberikan efek jera dengan tindakan keras seperti menaplok.

\section{B. Saran}

Adapun saran yang dapat disampaikan berdasarkan hasil penelitian tindakan ini, yaitu:

1. Bagi orang tua sebaiknya dalam memberikan pendidikan karakter ataupun 
penanaman budaya $5 \mathrm{~S}$ terhadap anak dapat dilakukan dengan cara yang baik.

2. Bagi anak hendaknya dalam menerapkan penanaman budaya 5S Senyum, Sapa, Salam, Sopan, Santun) dilakukan dengan baik dimanapun berada tanpa membedakan siapa orangnya yang dihadapi.

\section{DAFTAR RUJUKAN}

Ahmad, Susanto. 2009. Perkembangan anak usia dini : pengantar dalam berbagai aspeknya. Jakarta : Kencana.

Anggraeni, Fransiska Silvia., Azhar Haq., Fita Mustafida. 2019. Implementasi Pendidikan Karakter melalui budaya 5S (Senyum, Sapa, Salam, Sopan, Santun). Jurnal Pendidikan Madrasah Ibtidaiyah. Vol. 1 (2): 147-153.

Annisa. 2019. Budaya 5S (Senyum, Sapa, Salam, Sopan, Santun) dalam Pembentukan Karakter Siswa/Siswi di SD Muhammadiyyah Sapen Yogyakarta. Jurnal Teknologi Pendidikan Madrasah. Vol 2 (2): 187-204.

Asmani, Jamal Ma'mur. 2011. Buku panduan Internalisasi Pendidikan Karakter di Sekolah. Jogjakarta: Diva Press

Baedowi, Ahmad. 2015. Manajemen Sekolah Efektif Pengalaman madrasah Kusuma Bangsa. Jakarta: PT. Pustaka Alvabet.

Bungin, B. 2014. Penelitian Kualitatif: Komunikasi, Ekonomi, Kebijakan Publik, dan Sosial lainnya. Jakarta: Prenada Media Group.

Damayanti, Nidya. 2012. Buku Pintar Panduan Bimbingn Konseling. Yogyakarta: Araska.

E-book. 2014. Model Penilaian Pencapaian Kompetensi Peserta Didik Madrasah Tsanawiyah (MTs), Jakarta: Kementrian Agama RI Direktorat Jenderal Pendidikan islam Direktorat Pendidikan Madrasah.

Furkan, Nuril. 2014. The Implementation of Character Education through the School Culture in SMA Negeri 1 Dompu and SMA Negeri Kilo Dompu Regency. Journal of Literature, Language and Linguistics - An Open Access International Journal. Vol. 3 2014.

Ghufron, A. 2010. Integrasi Nilai-nilai Karakter
Bangsa pada Kegiatan Pembelajaran. (Online),

(http://journal.uny.ac.id/index.php/cp/ article/download/230/pdf 23, diaskes 10 November 2020).

Ginanjar, M. Hidayat. 2013. Keseimbangan Orangtua dalam Pembentukan Karakter Anak. Jurnal Pendidikan Islam. Vol 2 : 234

Gunawan, Heri. 2012. Pendidikan Karakter Konsep dan Implementasi. Bandung: Alfabeta

Herdiansyah, H. 2011. Metodologi Penelitian Kualitatif untuk ilmu-ilmu Sosial. Jakarta: Salemba Humanika.

Jonathan, Sarwono. 2006. Metode Penelitian Kuantitatif dan Kualitatif. Yogyakarta. Graha Ilmu.

Mardyanasari, M. 2020. Penanaman Sikap Toleransi Dalam Berelasi Siswa Melalui Budaya 5S di MA Muhammadiyah 1 Ponorogo (Doctoral dissertation, IAIN PONOROGO).

Maulidah, Fitrotul dan Hendrik Pandu Paksi. 2019. Implementasi Budaya 5S (Senyum, Sapa, Salam, Sopan, Santun) di SDN Suruh Sidoarjo. Jurnal Pendidikan Guru Sekolah Dasar. Vol 7 (4): 3285-3294.

Norbayah. 2017. Penanaman kebiasaan $5 S$ (Salam, Senyum, Sapa, Sopan, Santun) siswa Sekolah Dasar gugur pasar lama Banjarmasin. Tesis. Program Studi Kependidikan Islam. Universitas Islam Negeri Antasari. Banjarmasin

Pringgadini, Heni. 2018. Penanaman Karakter Sopan Santun Melalui Program 5S (Senyum, Sapa, Salam, Sopan, Santun) Pada Siswa Kelas IV SD Muhammadiyah 22 Sruni Surakarta. Skripsi. FKIP. Pendidikan Guru Sekolah Dasar Universitas Muhammadiyah Surakarta. Surakarta.

Putra, Kristya Septian. 2015. Implementasi Pendidikan Agama Islam Melalui Budaya Religius (Religius Culture) di Sekolah. Jurnal Kependidikan. Vol 3 (2):27.

Putri, Anita Erlisa. 2020. Pengaruh Penanaman Budaya 5S dan Pembiasaan Salat Berjamaah terhadap Karakter Religius Siswa Kelas X dan XI MA Ma'arif Klego 
Ponorogo. Skripsi. Fakultas Tarbiyah dan Ilmu Keguruan, Pendidikan Agama Islam, Institut Agama Islam Negeri (IAIN): Ponorogo.

Rahayu, Sri Wening., Bambang Budi Wiyono., I Nyoman Sudana Degeg., Ibrahim Bafadal. 2017. Implementasi of Character Education Through Culture 5S (Senyum, Sapa, Salam, Sopan, Santun) at State Junior High School 2 Ngawi (SMP N 2 Ngawi) East Java Indonesia. Based Education Journal. Vol 1 (2): 131-133.

Rahmawati, Endis Citra Pradinda., Dkk. 2019. Media dan Perkembangan Budaya. Intrans Publishing Group: Universitas Muhammadiyah Malang.

Rohani, Yayuk Rahayu, Yulianingsih M. 2018. Peran guru pendidikan kewarganegaraan dalam menanamkan nilai sopan santun. Jurnal Pendidikan Kewarganegaraan. Vol 2 (1): 321

Sudaryono. 2017. Metodologi Penelitian. Jakarta: PT Raja Grafindo Persada.

Sudrajat, A. 2011. Mengapa Pendidikan karakter?.Jurnal Pendidikan Karakter. Vol 1 (1).
Sugiyono. 2016. Metode Penelitian Administrasi dilengkapi dengan Metode R\&D. Bandung: CV Alvabeta.

Sukiyat. 2020. Strategi Implementasi Pendidikan Karakter. CV. Jakad Media Publishing: Surabaya.

Suryadi, Rudi Ahmad., Aguslani Mushlih. 2019. Desain dan Perencanaan Pembelajaran. CV Budi Utama: Yogyakarta.

Suryani, Liliek. 2017. Upaya meningkatkan Sopan Santun berbicara dengan teman sebaya melalui bimbingan kelompok. Jurnal Mitra Pendidikan. Vol 1 (1): 113.

Suyanti., Maya Kartika Sari., Sri Budyartati. 2020. Pembinaan Kultur Sekolah Sebagai Upaca Pembentukan Karakter di SD Manisrejo 1 Madiun. Jurnal Bidang Pendidikan Dasar. Vol 4 (2): 186-187.

Tim Duta Madani., Fathan Hasan AH., Sutisna Endang. 2017. Pasti Bisa Pendidika Agama Islam dan Budi Pekerti untuk SMP/MTS Kelas $X$. Penerbit Duta: Bandung. 